\title{
Karyotypes in Four Diploid Species of Chrysanthemum
}

\author{
Ryuso Tanaka and Naomasa Shimotomai \\ Botanical Institute, Faculty of Science, Hiroshima University, \\ Hiroshima, Japan
}

Received January 10, 1961

\section{Introduction}

In the present paper karyotypes of Chrysanthemum lineare, Ch. vulgare, $C h$. vulgare var. boreale, $C h$. rupestre and $C h$. nipponicum were reported. These plants are native to Japan, except $C h$. vulgare, and differ from each other in natural habitat as well as their external morphology (Shimotomai 1935 and Kitamura 1948). According to Kitamura (1940) they fall into different sections or subsections.

The chromosome number of these species were reported to be $2 \mathrm{n}=18$ (Tahara 1914-1915, 1921, Shimotomai 1933, 1937, Sugiura 1937, Nagami 1957). Shimotomai and Takemoto $(1936,1939)$ studied the karyotypes of Ch. lineare and $\mathrm{Ch}$. nipponicum and found differences in both chromosome length and number of satellites. Nagami (1957) in his study on the karyotype of Ch. rupestre did not find any satellites in this species.

Recently, one of the present authors (Tanaka $1959 \mathrm{a}$ and b) studied the karyotypes of two diploid species, Ch. boreale and $C h$. Makinoi, using a new stain technique developed by Tjio and Levan (1950) and Shimotomai et al. (1956), and observed satellites in chromosomes of these species. In the present investigation further details of the karyotypes of four Chrysanthemum species were observed by applying the new stain technique.

\section{Materials and methods}

Clones of four species and a variety, Ch. lineare, Ch. vulgare, $C h$. vulgare var. boreale, Ch. rupestre and Ch. nipponicum, were collected from the native habitat of the species. The localities where the clones were collected are shown in Table 1 . The clones were grown in pots in the experimental garden at the Hiroshima University. Validating specimens studied were deposited in the Herbarium of the Botanical Institute of the Hiroshima University.

Cytological studies were made from root tip and bud materials. For the study of somatic chromosomes in root tips, the method of Tjio and Levan (1950) modified by Shimotomai et al. (1956) was used. For the study of meiotic chromosomes the method of squashing with aceto-orcein or aceto- 
carmine was used. These methods were described in a previous report (Tanaka 1959a).

\section{Results}

1. Ch. lineare Matsumura. Figs. 1,5 and 9; Table 2.

Fifteen clones were collected from a small swamp in Yatsugi in the province of Bingo. All of the clones collected were found to be diploid with $2 \mathrm{n}=18$ chromosomes. The chromosomes were long and showed slight variation in length. They varied in length from about $16 \mu$ to $12 \mu$. They were identified as nine pairs and classified into five pairs with median centromeres and four pairs with submedian centromeres.

Table 1. Localities and chromosome number of Chrysanthemum lineare, Ch. vulgare, Ch. vulgare var. boreale, Ch. rupestre, and Ch. nipponicum

\begin{tabular}{llcc} 
& \multicolumn{1}{c}{ Localities } & $\begin{array}{c}\text { Chromosome } \\
\text { number (2n) }\end{array}$ & $\begin{array}{c}\text { Number of } \\
\text { clones }\end{array}$ \\
Ch. lineare & Yatsugi, Prov. Bingo & 18 & 15 \\
Ch. vulgare & Marburg Botanical Garden, Germany & 18 & 5 \\
Ch. vulgare var. boreale & $\begin{array}{l}\text { Oshidomari, the island of Rishiri } \\
\text { (Hokkaido) }\end{array}$ & 18 & 2 \\
Ch. rupestre & Utro, Shiretoko peninsula (Hokkaido) & 18 & 3 \\
Ch. nipponicum & Mt. Osawadake (2700 m), Prov. Kai & 18 & 3 \\
& Tanesashi, Prov. Mutsu & 18 & 11 \\
& Kinkazan, Prov. Rikuzen & 18 & 10 \\
& Hirakata, Prov. Hitachi & 18 & 11 \\
\hline
\end{tabular}

Chromosome $1^{1}$, the longest chromosome of the complement, has a median centromere. Chromosome 2 is the second longest chromosome and has a submedian centromere. Chromosomes 3 and 4 are the medium length chromosomes and have a submedian centromere. Chromosomes 5 and 6 are also the medium length chromosomes and have a median centromere. Chromosome 7 is one of the shorter chromosomes and has a median centromere. Chromosome 8 is also one of the shorter chromosomes and has a submedian centromere. Chromosome 9 is another shorter chromosome and has a median centromere. This is about $3 / 4$ the length of chromosome 1 .

Satellites were found in three pairs of chromosomes 4,7 and 8 . The size of satellites of the three chromosomes were similar with about $0.5 \mu$ in diameter.

Meiosis was normal with the formation of nine bivalents at diakinesis and metaphase I. The nine bivalents were either ring or rod form. Most PMCs had five ring bivalents and four rod bivalents. Chromosomes in most

1 In the present paper chromosomes are designated by Arabic numerals according to the recommended rule of the International Committee on Genetic Symbols and Nomenclature at Paris (1957). The letters of chromosomes $a, b, c, d, e, f, g, h$ and $i$ in earlier reports (Tanaka 1959a, 1959b, 1959c, 1959d, 1960) should be changed to Arabic numerals 1, 2, 3 , $4,5,6,7,8$ and 9 , respectively. 

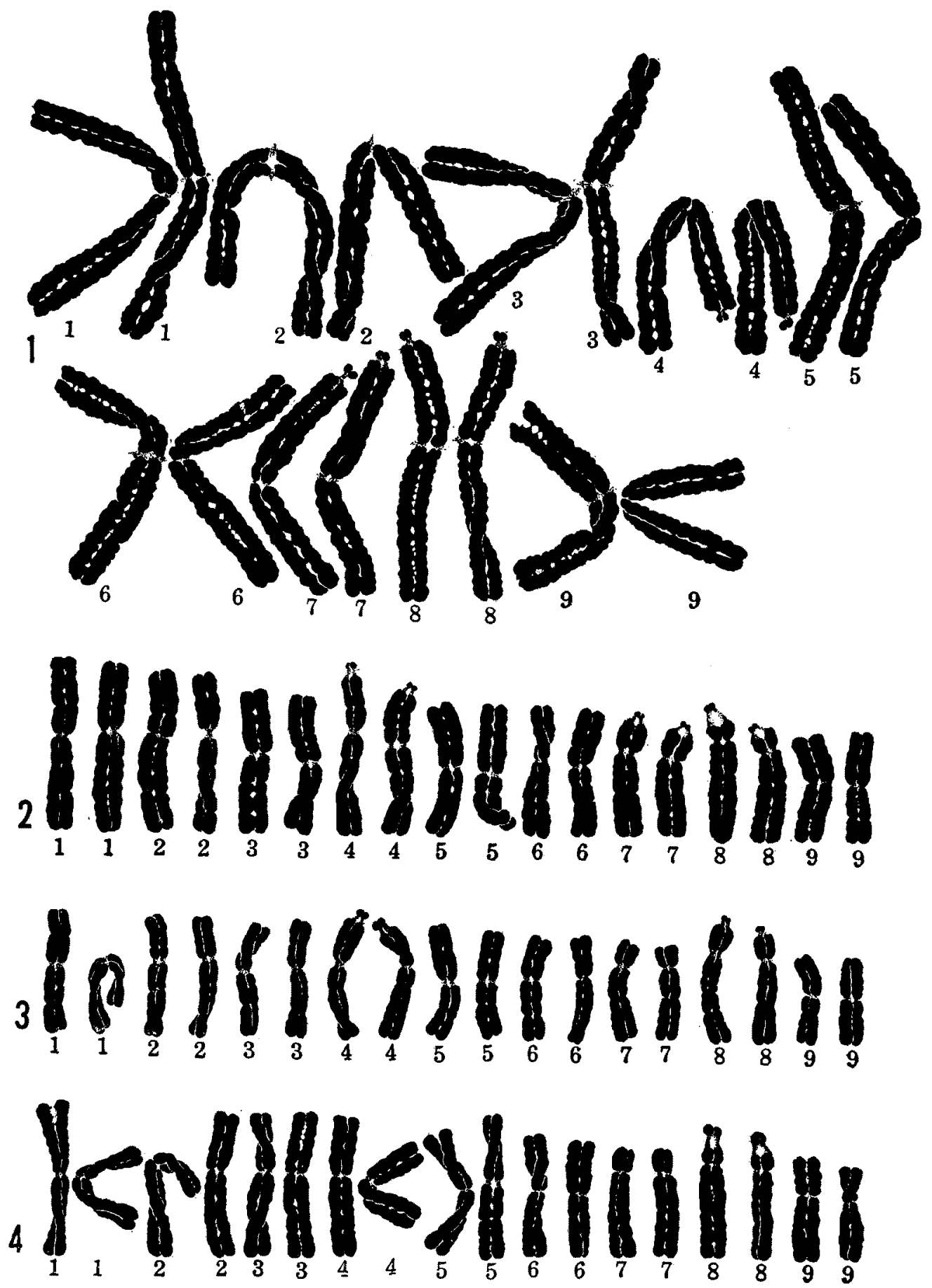

Figs. 1-4. Somatic chromosomes in the four species of Chrysanthemum. 1, chromosomes of Ch. lineare, $2 \mathrm{n}=18$. (Text-figure 5). 2, chromosomes of Ch. vulgare var. boreale, $2 \mathrm{n}=18$. (Text-figure 7). 3, chromosomes of Ch. rupestre, $2 \mathrm{n}=18$. (Text-figure 8 ). 4, chromosomes of Ch. nipponicum, $2 \mathrm{n}=18$. (Text-figure 6). $\times 3100$. 
PMCs separated normally to both poles at anaphase I. In a few PMCs one or two lagging chromosomes were observed. However, no micronucleus was seen in the cells at telophase I and II. All of the tetrads observed were without micronucleus or microcyte.

Table 2. Measurements of somatic chromosomes of Chrysanthemum lineare treated with 8-oxyquinoline

\begin{tabular}{cccc}
\hline Chromosomes & Length in $\mu$ & Relative length & Index \\
\hline 1 & $7.8+8.1=15.9$ & 6.5 & 0.96 \\
1 & $7.8+8.0=15.8$ & 6.5 & 0.98 \\
2 & $6.7+9.1=15.8$ & 6.5 & 0.74 \\
2 & $6.7+9.1=15.8$ & 6.5 & 0.74 \\
3 & $6.8+8.6=15.4$ & 6.3 & 0.79 \\
3 & $6.4+7.6=14.0$ & 5.7 & 0.84 \\
$4^{*}$ & $5.3+7.5=12.8$ & 5.3 & 0.71 \\
$4^{*}$ & $5.3+7.5=12.8$ & 5.3 & 0.71 \\
5 & $6.9+7.4=14.3$ & 5.9 & 0.93 \\
5 & $6.6+7.1=13.7$ & 5.6 & 0.93 \\
6 & $6.3+7.1=13.4$ & 5.5 & 0.89 \\
6 & $6.0+6.5=12.5$ & 5.1 & 0.92 \\
$7^{*}$ & $5.8+5.8=11.6$ & 4.8 & 1.00 \\
$7^{*}$ & $5.8+5.8=11.6$ & 4.8 & 1.00 \\
$8^{*}$ & $4.6+7.4=12.0$ & 4.9 & 0.62 \\
9 & $4.5+7.4=11.9$ & 4.9 & 0.61 \\
9 & $5.8+6.4=12.2$ & 5.0 & 0.91 \\
$*$ & $5.8+6.4=12.2$ & 5.0 & 0.91 \\
\hline satellite chromosome & & & \\
\hline
\end{tabular}

Three bivalents were found attached to a nucleolus at diakinesis (Fig. 9). Each of them was $V$-shaped and attached to the nucleolus at the terminal position of both arms. A satellite was found on the arm of homo. logous chromosomes of the three bivalents. These three bivalents were identified as chromosomes 4,7 and 8 .

2. Ch. vulgare Bernh. and Ch. vulgare var. boreale Makino. Figs. 2, 7 and 10 ; Table 3.

Ch. vulgare is a widespread species in subarctic areas of Eurasia. In Japan it is found in Hokkaido. Two clones of this species were collected from Oshidomari on the island of Rishiri. They grew in the slopes of foothills. Also, three clones of this species were collected from Utro on the Shiretoko peninsula. These clones grew in the rocky slopes exposed to sea. In addition to the Japanese clones, five clones of this species were received from Marburg Botanical Garden, Germany. Kitamura (1940) reported that the clones from both Oshidomari and Utro were $C h$. vulgare var. boreale Makino. Observations on the present materials showed no morphological differences between European clones and Japanese clones, except the latter had greater pubescence in leaves and stems.

The clones collected from both Japan and Germany had the same chromosome number, $2 \mathrm{n}=18$, and showed similar karyotypes. The chromosomes 
varied in length from about $8 \mu$ to $5 \mu$. The chromosomes of this species were smaller than those of $C h$. lineare.

The nine pairs of chromosomes were classified into three pairs of chromosomes with median centromeres, four pairs with submedian centromeres, and two pairs with subterminal centromeres.

The longest chromosome (chromosome 1) had a submedian centromere and was about two times the length of the shortest chromosome (chromosome 9).

Satellites were found in three pairs of chromosomes 4, 7 and 8. Chromosome 4 , one of the longer chromosomes of the complement, had a submedian centromere. Both chromosomes 7 and 8 were the shorter chromosomes of the complement and had subterminal centromeres.

Meiosis in the two clones from Oshidomari, three clones from Utro and five clones from Marburg Botanical Garden showed similar chromosome behaviour. Nine bivalents appeared at
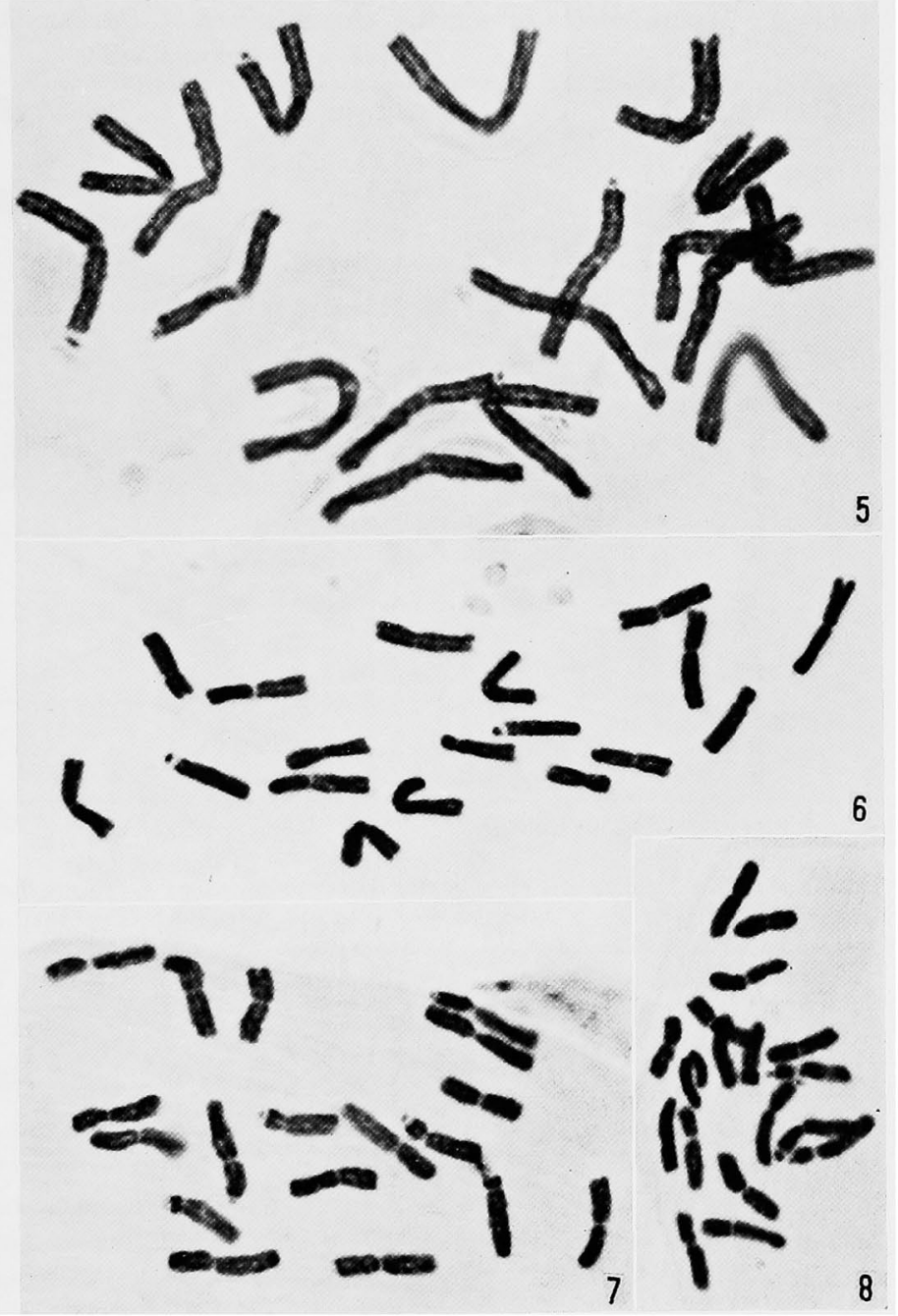

Figs. 5-8. Photomicrographs of somatic chromosomes in the four species of Chrysanthemum. 5, chromosomes of Ch. lineare, 2n $=18$. 6 , chromosomes of $C h$. nipponicum, $2 \mathrm{n}=18.7$, chromosomes of Ch. vulgare var. boreale, $2 \mathrm{n}=18$. 8, chromosomes of $\mathrm{Ch}$. rupestre, $2 \mathrm{n}=18 . \times 1600$.

equatorial plate at metaphase I. At anaphase I, they moved to the respective poles. In few PMCs precocious separation of bivalents was observed at anaphase I. The form of the bivalents was ring or rod. Most PMCs had six ring and three rod bivalents. 
At diakinesis three bivalents were found attached to a nucleolus (Fig. 10). Each of them was V-shaped and attached to the nucleolus at the terminal position of both arms. The three bivalents possessed satellites on the arm of homologous chromosomes. They were identified as chromosomes 4,7 and 8 .

Table 3. Measurements of somatic chromosomes of Chrysanthemum vulgare var. boreale treated with 8-oxyquinoline

\begin{tabular}{cccc}
\hline Chromosomes & Length in $\mu$ & Relative length & Index \\
\hline 1 & $3.5+4.4=7.9$ & 7.2 & 0.80 \\
1 & $3.1+4.4=7.5$ & 6.8 & 0.70 \\
2 & $3.1+4.5=7.6$ & 6.9 & 0.69 \\
2 & $2.4+4.3=6.7$ & 6.1 & 0.56 \\
3 & $2.9+3.5=6.4$ & 5.8 & 0.83 \\
3 & $2.9+3.2=6.1$ & 5.6 & 0.91 \\
$4^{*}$ & $2.2+4.6=6.8$ & 6.2 & 0.48 \\
$4^{*}$ & $2.2+4.0=6.2$ & 5.7 & 0.55 \\
5 & $3.0+3.0=6.0$ & 5.5 & 1.00 \\
5 & $2.9+3.1=6.0$ & 5.5 & 0.94 \\
6 & $2.5+3.5=6.0$ & 5.5 & 0.71 \\
6 & $2.5+3.2=5.7$ & 5.2 & 0.78 \\
$7^{*}$ & $1.5+4.0=5.5$ & 5.0 & 0.38 \\
$7^{*}$ & $1.4+3.8=5.2$ & 4.7 & 0.37 \\
$8^{*}$ & $0.7+4.6=5.3$ & 4.8 & 0.15 \\
9 & $0.7+4.2=4.9$ & 4.5 & 0.17 \\
9 & $2.2+2.7=4.9$ & 4.5 & 0.81 \\
9 & $2.2+2.6=4.8$ & 4.4 & 0.85 \\
\hline
\end{tabular}

* satellite chromosome

Table 4. Measurements of somatic chromosomes of Chrysanthemum rupestre treated with 8-oxyquinoline

\begin{tabular}{cccc}
\hline Chromosomes & Length in $\mu$ & Relative length & Index \\
\hline 1 & $2.4+3.1=5.5$ & 6.4 & 0.77 \\
1 & $2.4+3.1=5.5$ & 6.4 & 0.77 \\
2 & $2.0+3.3=5.3$ & 6.2 & 0.61 \\
2 & $1.8+3.3=5.1$ & 5.9 & 0.55 \\
3 & $2.1+2.8=4.9$ & 5.7 & 0.75 \\
3 & $2.0+2.8=4.8$ & 5.6 & 0.71 \\
$4^{*}$ & $1.8+3.3=5.1$ & 5.9 & 0.55 \\
$4^{*}$ & $1.8+3.3=5.1$ & 5.9 & 0.55 \\
5 & $2.4+2.4=4.8$ & 5.6 & 1.00 \\
5 & $2.2+2.4=4.6$ & 5.3 & 0.92 \\
6 & $2.0+2.7=4.7$ & 5.5 & 0.74 \\
6 & $1.9+2.7=4.6$ & 5.3 & 0.70 \\
7 & $1.1+3.3=4.4$ & 5.1 & 0.33 \\
7 & $1.0+3.2=4.2$ & 4.9 & 0.31 \\
$8^{*}$ & $1.1+3.8=4.9$ & 5.7 & 0.29 \\
$8^{*}$ & $1.0+3.7=4.7$ & 5.5 & 0.27 \\
9 & $1.8+2.1=3.9$ & 4.5 & 0.86 \\
9 & $1.8+2.1=3.9$ & 4.5 & 0.86 \\
\hline
\end{tabular}

* satellite chromosome 
3. Ch. rupestre Matsumura et Koidzumi. Figs. 3, 8 and 11; Table 4. Three clones were collected from Mt. Osawadake $(2700 \mathrm{~m})$ in the province of Kai. According to Seki (1957) they grew on rocky soils near the top of Mt. Osawadake. These clones, which were typical of the species, were found to have $2 \mathrm{n}=18$ chromosomes.

The chromosomes of this species were smaller than those of Ch. vulgare.

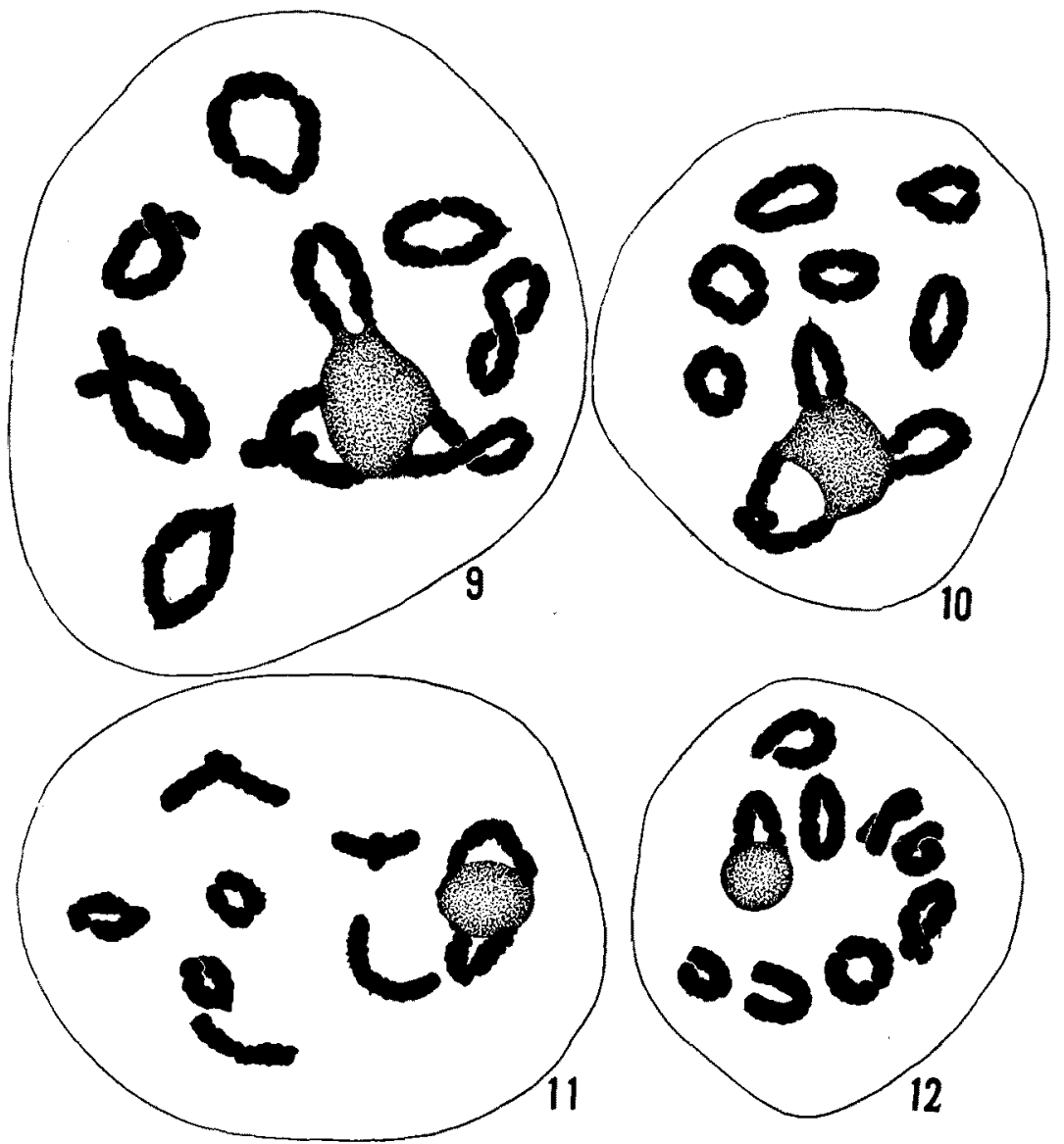

Figs. 9-12. Meiotic chromosomes at diakinesis in the PMCs of the four species of Chrys. anthemum. 9, chromosomes of Ch. lineare, 9II. Of nine bivalents three attach to a nucleolus. 10, chromosomes of Ch. vulgare var. boreale, 9II. Three bivalents attach to a nucleolus. 11, chromosomes of Ch. rupestre, 9II. Two bivalents attach to a nucleolus. 12 , chromosomes of Ch. nipponicum, $9_{\mathrm{II}}$. One bivalent attaches to a nucleolus. $\times 1200$.

They varied in length from about $6 \mu$ to $4 \mu$. The nine pairs of chromosomes were classified into two pairs of chromosomes with median centromeres, five pairs of chromosomes with submedian centromeres, and two pairs of chromosomes with subterminal centromeres. The longest chromosome (chromosome 1) had a submedian centromere, while the shortest chromosome (chromosome 9) had a median centromere.

In contrast with the observations of Nagami (1957), satellites were observed 
in the present materials. The satellites were found in two pairs of chromosomes 4 and 8 . Chromosome 4 had a submedian centromere and chromosome 8 had a subterminal centromere. The former was one of the longer chromosomes of the complement and the latter was one of the shorter chromosomes.

Meiosis in PMCs was normal with the formation of nine bivalents at diakinesis and metaphase I. The form of the bivalents was ring or rod. Most PMCs had three ring and six rod bivalents. At diakinesis two bivalents were found attached to a nucleolus (Fig. 11). A satellite was observed on homologous chromosomes of the two bivalents. These two bivalents were identified as chromosomes 4 and 8 .

4. Ch. nipponicum Matsumura. Figs. 4,6 and 12 ; Table 5.

This is a species growing in coastal slopes of northern Pacific coast of Japan (Shimotomai 1935). Thirty two clones were collected from three localities: Tanesashi in the province of Mutsu; Kinkazan in the province of Rikuzen; and Hirakata in the province of Hitachi. These clones were morphologically similar to the type specimen deposited in the Herbarium of Tokyo University, with the exception of the clones from Hirakata which had broader leaves. All of the clones flowered in late September. The clones from

Table 5. Measurements of somatic chromosomes of Chrysanthemum nipponicum treated with 8-oxyquinoline

\begin{tabular}{cccc}
\hline Chromosomes & Length in $\mu$ & Relative length & Index \\
\hline 1 & $3.3+3.5=6.8$ & 6.6 & 0.94 \\
1 & $3.1+3.5=6.6$ & 6.4 & 0.89 \\
2 & $2.6+4.2=6.8$ & 6.6 & 0.62 \\
2 & $2.6+4.0=6.6$ & 6.4 & 0.65 \\
3 & $2.6+3.8=6.4$ & 6.2 & 0.68 \\
3 & $2.6+3.8=6.4$ & 6.2 & 0.68 \\
4 & $2.7+3.6=6.3$ & 6.1 & 0.75 \\
4 & $2.6+3.4=6.0$ & 5.8 & 0.76 \\
5 & $2.8+3.3=6.1$ & 5.9 & 0.85 \\
5 & $2.8+3.3=6.1$ & 5.9 & 0.85 \\
6 & $2.5+3.1=5.6$ & 5.4 & 0.81 \\
6 & $2.4+2.9=5.3$ & 5.1 & 0.83 \\
7 & $1.0+4.0=5.0$ & 4.9 & 0.25 \\
7 & $1.0+3.8=4.8$ & 4.7 & 0.26 \\
$8 *$ & $0.7+4.2=4.9$ & 4.8 & 0.17 \\
$8^{*}$ & $0.7+4.0=4.7$ & 4.6 & 0.18 \\
9 & $1.6+2.8=4.4$ & 4.3 & 0.57 \\
9 & $1.5+2.7=4.2$ & 4.1 & 0.56 \\
$*$ satellite chromosome & & & \\
\hline
\end{tabular}

Tanesashi flowered about one week earlier than those from the other regions.

The chromosome number was determined to be $2 \mathrm{n}=18$ for all clones collected. Karyotypes of two clones from each locality were studied. All of the clones showed similar karyotypes. The chromosomes were larger than those of Ch. rupestre but smaller than those of $\mathrm{Ch}$. vulgare and $\mathrm{Ch}$. lineare. 
They varied in length from about $7 \mu$ to $4 \mu$. They were classified into three pairs of chromosomes with median centromeres, four pairs of chromosomes with submedian centromeres, and two pairs of chromosomes with subterminal centromeres. The longest chromosome (chromosome 1) had a median centromere and was approximately one and a half times that of the shortest chromosome (chromosome 9).

Satellites were found in a pair of chromosomes 8. The satellite chromosome was the second shortest chromosome of the complement and had a subterminal centromere. The satellites were larger than those of $\mathrm{Ch}$. lineare, Ch. vulgare and $C h$. rupestre.

The observation on the karyotypes were similar to that reported by Shimotomai and Takemoto $(1936,1939)$.

Meiosis in all clones showed similar behaviour. Meiosis was normal with the formation of nine bivalents at metaphase $I$ and nine chromosomes at metaphase II. The nine bivalents at metaphase I were of ring or rod form. Most PMCs had three ring and six rod bivalents.

At diakinesis one bivalent was found attached to a nucleolus at the terminal position of both arms (Fig. 12). A satellite was found on the arm of homologous chromosomes of this bivalent. This bivalent was identified as chromosome 8 .

\section{Discussion}

Karyotypes of the four species, Ch. lineare, Ch. vulgare, Ch. rupestre and $C h$. nipponicum, were found to differ from each other in chromosome size. Ch. lineare had the longest chromosomes, followed by $\mathrm{Ch}$. vulgare, $\mathrm{Ch}$. nipponicum and $\mathrm{Ch}$. rupestre. The chromosomes of $\mathrm{Ch}$. lineare were about two times longer than those of $C h$. vulgare. The differences in chromosome size indicate the relatively distant relationships of the four species.

The position of centromer $s$ in the chromosomes of $C h$. lineare was not as variable as those of the other species. The chromosomes of the complement of $\mathrm{Ch}$. lineare possessed median or submedian centromeres. No chromosomes with subterminal a $r$ terminal centrorneres were found in $C h$. lineare. The chromosome complements of Ch. vulgare, Ch. rupestre and $C h$. nipponicum, on the other hand, possessed two pairs of chromosomes with subterminal centromeres. On the basis of the position of centromeres and the size of chromosomes, $\mathrm{Ch}$. lineare appears to be the most primitive species.

In $C h$. lineare three pairs of satellite chromosomes were found. The same number of satellite chromosomes was found in $C h$. vulgare, while $C h$. rupestre possessed tw? pairs of satellite chromosomes and $C h$. nipponicum only one pair of satellite chromosomes. Therefore, the species with longer chromosomes had more satellite chromosomes than the species with shorter chromosomes.

Differences in satellite chromosomes also may provide additional light on 
the evolutionary trends of the four species. Tanaka (1959a) found a decrease in satellite chromosomes of $\mathrm{Ch}$. boreale following its speciation. He also found that Ch. Makinoi, which is considered to be an advanced species, had two pairs of satellite chromosomes (Tanaka 1959b). In these two species the satellites of chromosome 7 have disappeared. Similar disappearance of satellites might have occurred in $C h$. rupestre and $C h$. nipponicum. In $C h$. nipponicum, moreover, satellites of another chromosome (chromosome 4) have been lost. The disappearance of satellites was found to have resulted in a loss of the nucleolus organizing capacity. The decrease of nucleolar chromosomes may be partially responsible for the evolution of $\mathrm{Ch}$. rupestre and $C h$. nipponicum.

\section{Summary}

1. The karyotypes of four diploid species, Ch. lineare, $C h$. vulgare, Ch. rupestre, and Ch. nipponicum, were found to differ from each other in chromosome size, in the position of centromeres and in the number of satel. lite chromosomes.

2. Ch. lineare had the longest chromosomes, followed by Ch. vulgare, Ch. nipponicum and $C h$. rupestre.

3. The chromosome complement of $\mathrm{Ch}$. lineare was without chromosomes with subterminal centromeres, while the chromosome complements of $C h$. vulgare, $C h$. rupestre and $C h$. nipponicum had two pairs of chromosomes with subterminal centromeres.

4. Ch. lineare and $C h$. vulgare had three pairs of satellite chromosomes, Ch. rupestre had two pair of satellite chromosomes, and Ch. nipponicum had only one pair of satellite chromosomes.

5. The satellite chromosomes of the four species were found to be a nucleolar chromosome.

6. Species with shorter chromosomes had fewer satellite chromosomes than those with longer chromosomes. The former were presumed to be the advanced species and the latter the primitive species. Ch. lineare is presumed to be the most primitive among the four species.

\section{Literature cited}

Kitamura, S. 1940. Compositae Japonicae. Pars Secunda. Memoirs Coll. Sci. Kyoto Imp. Univ., Series B 15 (3), Art. 9: 258-446.

- 1948. Kiku (The Chrysanthemum). Tokyo. (Japanese).

Nagami, S. 1957. A preliminary report on the chromosome of Chrysanthemum rupestre. Jap. Jour. Genet, 32: 83-74. (Japanesa with English résumé).

Seki, T. 1957. The general survey of flora in Mt. Akaishi, South Japanese Alps. Seibutsugakkaishi 7: 35-44. (Japanesə).

Shimotomai, N. 1933. Zur Karyogenetik der Gattung Chrysanthemum. Jour. Sci. Hiroshima Univ., Series B, Div. 2, 1 (3): 1-100.

$\therefore$ 1935. Ecology and cytogenetics in Chrysanthèmum. Tokyo. (Japanese). 
- 1937. Chromosomenzahlen bei einigen Arten von Chrysanthemum. Zaitschr. ind. Abstamm. u. Vererb. 74: 30-33.

- and T. Takemoto. 1933. Uber die Morphologie der Chromosomen bei 6 Arten von Chrysanthemum. Bot. Mag., Tokyo 50: 324-331. (Japanese with German résumé).

- and - 1939. ibid. Jour. Sci. Hiroshima Univ., Series B, Div, 2, 3 (13): 201-204. (German).

- Tanaka, R., Masumori, S. and Ishiguro, M. 1956. Uber die Polyploidie und geographische Verbreitung bei Chrysanthemum japonense Nakai. Bot. Mag. Tokyo 69: 515-518. (Japanese with German résumé).

Sugiura, T. 1937. Studies on the chromosome numbers in higher plants, with special reference to cytokinesis, II. Cytologia, Fujii Jub. Vol.: 845-849.

Tahara, M. 1914-1915. Cytological studies on Chrysanthemum. Bot. Mag., Tokyo 29 (336): 491-493, (337-339): 6, 7, 9, 15, (340): 48-59. (Japanese with English résumé).

- 1921. Cytologische Studien und einigen Kompositen. Jour. Coll. Sci. Imp. Univ. Tokyo 43: Art. 7.

Tanaka, R. 1959a. On the speciation and karyotypes in diploid and tetraploid species of Chrysanthemum I. Karyotypes in Chrysanthemum boreale $(2 \mathrm{n}=18)$. Jour. Sci. Hiroshima Univ. Series B, Div, 2, 9: 1-16.

- 1959b. ibid. II. Karyotypes in Chrysanthemum Makinoi $(2 \mathrm{n}=18)$. ibid. 9: 17-30.

- 1959c. ibid. III. Meiosis in the $\mathrm{F}_{\mathrm{l}}$-hybrids of Chrysanthemum boreale $\times$ Ch. Makinoi. ibid. 9: 31-40.

- 1959d. idid. IV. Chrysanthemum wakasaense $(2 \mathrm{n}=33)$. ibid. 9: 41-58.

- 1960. ibid. V. Chrysanthemum Yoshinaganthum (2n=33). Cytologia 25 (1): 43-58.

Tjio, J. H. and Levan, A. 1950. The use of oxyquinoline in chromosome analysis. Anal. Est. Exper. de Aula Dei 2: 21-64. 